\title{
Natural and induced T regulatory cells in cancer
}

\section{Dennis O. Adeegbe and Hiroyoshi Nishikawa*}

Experimental Immunology, Immunology Frontier Research Center, Osaka University, Suita, Japan

\section{Edited by:}

Eyad Elkord, United Arab Emirates University, UAE, University of Salford and University of Manchester, UK

\section{Reviewed by:}

Axel Kallies, The Walter and Eliza Hall Institute of Medical Research, Australia

Yi-chi Kong, Wayne State University School of Medicine, USA

Nathan Karin, Technion - Israel Institute of Technology, Israel

\section{*Correspondence:}

Hiroyoshi Nishikawa, Experimental Immunology, Immunology Frontier Research Center, Osaka University, 3-1 Yamadaoka, Suita, Osaka 565-0871, Japan

e-mail: nisihiro@ifrec.osaka-u.ac.jp
CD4+Foxp3+ T regulatory (Treg) cells control many facets of immune responses ranging from autoimmune diseases, to inflammatory conditions, and cancer in an attempt to maintain immune homeostasis. Natural Treg (nTreg) cells develop in the thymus and constitute a critical arm of active mechanisms of peripheral tolerance particularly to self antigens. A growing body of knowledge now supports the existence of induced Treg (iTreg) cells which may derive from a population of conventional CD4+T cells. The fork-head transcription factor (Foxp3) typically is expressed by natural CD4+ Treg cells, and thus serves as a marker to definitively identify these cells. On the contrary, there is less consensus on what constitutes iTreg cells as their precise definition has been somewhat elusive. This is in part due to their distinct phenotypes which are shaped by exposure to certain inflammatory or "assault" signals stemming from the underlying immune disorder. The "policing" activity of Treg cells tends to be uni-directional in several pathological conditions. On one end of the spectrum, Treg cell suppressive activity is beneficial by curtailing $T$ cell response against self-antigens and allergens thus preventing autoimmune diseases and allergies. On the other end however, their inhibitory roles in limiting immune response against pseudo-self antigens as in tumors often culminates into negative outcomes. In this review, we focus on this latter aspect of Treg cell immunobiology by highlighting the involvement of $n$ Treg cells in various animal models and human tumors. We further discuss iTreg cells, relationship with their natural counterpart, and potential co-operation between the two in modulating immune response against tumors. Lastly, we discuss studies focusing on these cells as targets for improving anti-tumor immunity.

Keywords: Tregs, Foxp3, natural, induced, cancer, tumor, Interleukin-10, transforming growth factor $\beta$

\section{INTRODUCTION}

Early studies of $\mathrm{T}$ regulatory (Treg) cells, defined as a subset of $\mathrm{CD} 4+$ cells that co-express high levels of CD25, the high affinity IL-2 receptor $\alpha$-chain, demonstrated unequivocally that these cells are crucial for maintenance of peripheral self tolerance as their elimination led to development of multiple organ-specific autoimmune diseases (1). Subsequent studies identified foxp3, a member of the fork-head/winged-helix family of transcriptional factor as uniquely expressed by Treg cells and allowed for more precise phenotypic identification of these cells as CD25 alone was insufficient due to its upregulation on activated $\mathrm{T}$ cells (13 ). Endowed with highly suppressive machinery, it is now well established that CD4+Foxp3+ Treg cells regulate a diverse array of immune responses ranging from autoimmune disease, allergies, and transplant rejection, to infections and cancers (4). While generally beneficial in the former conditions, the inhibitory activity of Treg cells often antagonizes protective immunity in the latter settings. Depending on the microenvironment in which they are found, and potential stimuli eliciting their recruitment or presence at such sites, CD4+Foxp3+ Treg cells are now broadly described as natural or adaptive $(5,6)$. Natural CD4+Foxp3+ Treg cells are the better understood of the two with the central dogma being that the adaptive or "induced" cells are generally derived from existing pool of naïve conventional CD4+ T cells. Regardless of their origin, they share one key feature: their ability to potently suppress effector T cells (5). Although expression of Foxp3 generally identifies natural, thymus-derived CD4+ Treg cells, adaptive Treg cells may or may not express this transcription factor $(5,7,8)$.

Recent years have seen a surge in studies of cancer models and in humans highlighting the elevated levels of Treg cells in the tumor and/or in circulation $(9,10)$. This often correlates with poor antitumor effector response, hence compromised tumor immunity $(11,12)$. Whether the Foxp $3+$ cells widely described in many cancer settings are of natural or adaptive/induced type remains largely a bone of contention. This review focuses on the current knowledge about both subsets of Treg cells, their generation, phenotypic characteristics, and ill-defined roles as described in various tumor models and human cancers. Current therapeutic modalities geared toward Treg depletion and how they may impinge on recruited natural versus tumor-induced Treg (iTreg) cells are discussed.

\section{INDUCED/ADAPTIVE TREGS, MORE THAN JUST Foxp3+ CELLS}

Adaptive Tregs encompass a number of $\mathrm{CD} 4+$ cells with regulatory/suppressive capabilities $(7,8,13)$. Although "iTregs" is commonly used interchangeably with "adaptive Tregs," the former is perhaps a better nomenclature for all extrathymically derived CD4+ Treg cells. In this context, iTreg cells range from Tr1 cells, which are induced by IL-10, and secrete both IL-10 and TGF- $\beta$ (7), to TGF- $\beta$-producing Th3 cells (induced by oral antigen tolerizing 
conditions) (8), to peripheral naïve CD4+CD25-Foxp3- cells that become converted to Foxp3-expressing cells (13). Tr1 cells regulate immune responses against ubiquitous commensal organisms and promote tolerance in the gut, and accumulating evidence reveal they play key roles in other facets of adaptive immune response (7). Th3 cells on the other hand, appear critical in tolerance induced by oral antigen delivery (8). Both adaptive Treg cell types are induced in peripheral sites and have been described to generally lack expression of Foxp3 which distinctively identifies natural Treg (nTreg) cells of thymic origin $(2,3,14)$. In most tumor studies however, these cells have not been extensively described. Most of the attention on iTregs in tumor settings has largely focused on converted Foxp3-expressing cells mentioned above. Since both peripherally induced Foxp3+ as well as Foxp3 non-expressing CD4+ regulatory $\mathrm{T}$ cells (e.g., $\mathrm{Tr} 1-$ cells) are often discussed under the umbrella of "induced" Treg cells, for simplicity sake, the term iTreg in this review will be restricted to CD4+CD25-Foxp3- cells that have acquired Foxp3 expression. In order to do justice to their contributions in tumor settings, other Foxp3 non-expressing, peripherally induced CD4+ regulatory cells, specifically $\operatorname{Tr} 1$ cells, will be discussed separately as such in one section and the rest of our discussion will focus on Foxp3+ peripherally converted iTregs.

\section{NATURAL VERSUS INDUCED TREGS IN CANCER: ORIGIN AND ACCUMULATION}

Several lines of evidence reveal an accumulation of Treg cells both at peripheral sites (spleen, peripheral blood), and within the local tumor microenvironment [reviewed in Ref. (10, 12, 15)]. This often correlates with persistent tumor burden and poor anti-tumor effector response $(11,12)$. Importantly, a low CD8+ effector $\mathrm{T}$ cell number is also noted relative to the high proportion of Foxp3+ Treg cells in the peripheral blood and tumor tissue in many cancer patients (12) suggesting active recruitment of Foxp3+ Treg cells is a key feature of many tumors. Thus, a "guiltyby-association" analogy means that these tumor-infiltrating Treg cells must at least, in part, be responsible for dampening antitumor immunity, namely preventing effective tumor immunosurveillance. One outstanding issue however is the source of these cells, and this issue is currently a subject of debate within the tumor immunology community.

From current knowledge, the composition of Foxp3+ Treg cells within tumors and/or in circulation in human cancer patients remains poorly understood. There are a few possibilities: (1) They are nTregs recruited to the tumor site and actively expanding (1618); (2) They are a pool of induced, Foxp3-acquired Treg cells (iTregs) derived from converted CD25-cells $(19,20)$; (3) They are Tr 1 cells (discussed in the following section). In support of the first possibility, studies performed by Zou and colleagues demonstrated specific recruitment of pre-existing human Treg cells into tumors in a manner that was dependent on tumor-mediated CCL22 production and gradient (16). Another study demonstrated that Treg cells underwent substantial proliferation at tumor site and draining lymph node in response to TGF- $\beta$ secreted by immature DCs which themselves were a result of tumor cell modification (18). In either study however, the possibility that iTregs were also recruited or expanded at tumor site could not be excluded. The notion that tumor-infiltrating Tregs are likely expanded nTreg cells was further purported in a study that examined the TCR repertoire analysis of tumor-infiltrating Treg and T conventional cells (17). In this report, authors concluded that since the TCR repertoires of either population were largely non-overlapping, the tumor-infiltrating Tregs are likely of natural origin as a significant overlap would have been observed if a fair amount of CD25- cell conversion to Foxp3+ cells occurred.

Data supporting the second possibility comes from a number of studies (19-21). One of these demonstrated that in thymectomized, and anti-CD25-treated tumor-bearing mice, a population of Treg cells converted from CD25- cells developed (20). Anti-CD25 Treg depletion strategy has been described not to efficiently eliminate Treg cells (22). So the possibility remains that nTreg cells not touched by the treatment regimen expanded in this system. In any case, the thymectomy would have at least reduced any potential contribution by newly generated nTreg cells after anti-CD25 treatment cessation. Many tumors secrete TGF- $\beta$ that may directly or indirectly induce naïve $\mathrm{T}$ cell conversion to Foxp3+ iTregs $(19,20,23)$ Consistent with this, another group demonstrated that in a mouse prostate tumor model, tumorderived TGF- $\beta$ potentiated the conversion of CD4+CD25- T conventional cells into Foxp3-expressing, CD25+ iTreg cells (19). However, sole presence of iTreg or nTreg cells within the tumor need not be mutually exclusive as demonstrated by Zhou et al. Using an influenza hemagglutinin (HA)-expressing tumors along with HA TCR-transgenic T cells in an adoptive transfer system, they were able to demonstrate that both de novo generated adaptive and nTreg cells contributed to the pool of tumor-Treg cells (24). Thus, a more realistic view of their composition is that both adaptive and nTreg cells contribute to the total Treg pool affiliated with tumor microenvironment.

\section{Tr1 CELLS IN CANCER}

Not all regulatory CD4+ cells are endowed with Foxp3 suppressive machinery. As mentioned previously, IL-10-producing $\operatorname{Tr} 1$ cells fall under this umbrella of Foxp3-non-expressing cells. $\operatorname{Tr} 1$ cells by their original description in the early literature are CD4+CD25-, IL-10, and TGF- $\beta$-producing cells (7). The general consensus is that they are derived from a pool of naïve CD4+ T cells that are distinct from thymus-derived Foxp3+ cells. Suffice to say, they are seemingly low in frequency in an unperturbed immune environment but are readily detected in an environment rich in cytokines such as IL-10, justifying their label as adaptive or induced regulatory $\mathrm{T}$ cells.

Unlike CD4+Foxp3+ Treg cells, the involvement of Tr1 cells in tumors has not received as much attention. There are a number of studies showcasing the importance of these cells in tempering anti-tumor response, some dating back to pre-Foxp3 years (2530). In a cohort of Hodgkins lymphoma patients, an argument was made by Marshall and colleagues for a contributory role of CD4+ IL-10+ Tr1 cells toward ineffective clearance of Hodgkins lymphoma. This was in part based on their finding that these cells were present at elevated proportions in associated lymph nodes, and could suppress T cell response in corresponding PBMCs (26). The co-existence of the $\operatorname{Tr} 1$ cells with CD4+CD25+ (presumably natural Foxp3+) both of which were enriched in the lymph 
nodes in this particular study makes it difficult to ascertain to what extent, if any, the $\operatorname{Tr} 1$ cells played an inhibitory role. Whiteside and colleagues have reported extensively the presence of $\operatorname{Tr} 1$ cells in head and neck squamous-cell carcinoma (HNSCC) patients (10). Although relatively low in frequency in circulation, they were present in a sizable proportion in tumor-infiltrating lymphocytes (28). In vitro analysis of peripheral CD4+ cells in glioblastoma patient also revealed a prominent $\operatorname{Tr} 1$ response against tumor cells suggestive of an enriched population of $\operatorname{Tr} 1$ cells in this setting (27). In a protocol involving adoptive transfer of in vitro-cultured Th1-like cells to ovarian cancer patients, $\operatorname{Tr} 1$ cells were also shown to contribute to the total circulating Treg pool (30). In general, many of the analyses performed in these studies were dependent on stimulation of patient's PBMC with or without tumor antigens plus $\operatorname{Tr} 1$ cell-enhancing cytokines to showcase their existence, and demonstrate that cancer patients harbor more $\operatorname{Tr} 1$ cells than healthy individuals. Perhaps, most of the Tr1 cells in the periphery exist in precursor form and are only expanded at tumor site where antigen is ubiquitous and key cytokines such as IL-10 are abundant, similar to the in vitro simulations. The study performed by Bergmann et al., certainly is in agreement with this notion (28).

The mechanisms by which $\operatorname{Tr} 1$ cells might be induced within the tumor remains unclear. Some lines of evidence suggest that certain factors uniquely produced by tumor cells could facilitate an IL-10rich environment that ultimately fosters $\operatorname{Tr} 1$ cell induction $(10,27)$. In one report, cyclooxygenase-2 (COX-2) overexpressing glioma via Prostaglandin E2 (PGE2) synthesis induced mature DCs to express high levels of IL-10, which in turn induced CD4+ T cells that secreted copious amounts of IL-10 and TGF- $\beta$ (27). Furthermore, CD4+ T cells isolated from peripheral blood of glioblastoma patient showed marked IL-10 production against tumor cells indicating an enrichment of $\operatorname{Tr} 1$ cells within the peripheral CD4+ T cell pool in this patient. This sentiment was echoed by another study which demonstrated that in vitro, highly suppressive $\operatorname{Tr} 1$ cells were generated from CD4+CD25- T cells in the presence of autologous DCs and irradiated COX-2+ HNSCC cells or exogenous PGE2, with a cytokine cocktail that included IL-10 (29). Like the afore-mentioned study, the overall conclusion here is that COX-2 overexpression, and PGE2 production by HNSCC plays a key role in the induction of $\operatorname{Tr} 1$ cells in this malignancy. The $\operatorname{Tr} 1$ cells in this study however, were shown to have some Foxp3 expression.

One important point is that a unifying phenotype that definitively identifies these CD4+ Tr1 cells is yet to be agreed upon. Besides being CD25 negative, IL-10, and TGF- $\beta$-producing, their Foxp3 status remains a divisive subject. Some studies showed they express variable Foxp 3 levels $(28,29,31)$, others described them as Foxp3 negative, or foxp3 status was not addressed (26, 27, 30, 32, 33). The differences between these studies may likely stem from experimental designs although it can be argued that the stimulatory conditions used in some of the in vitro assays to amplify $\operatorname{Tr} 1$ cells are also conducive to Foxp3 induction in lieu of the fact that conventional human $\mathrm{T}$ cells can upregulate FOXP3 upon activation (34). Regardless of how they are described, $\operatorname{Tr} 1$ cells, like their natural counterparts, are capable of exhibiting potent suppressive functions as demonstrated in some of the above-mentioned studies.
With respect to their perceived function within the tumor microenvironment, it remains a possibility that they co-operate with nTregs, a notion that has been suggested by others (35). The dichotomy that $\operatorname{Tr} 1$ cells are increased in frequency in advanced cancer stage and also in patients who had no evidence of active disease following oncologic treatments when compared with early stage raises the possibility that they may play differing roles under varying tumor burdens (28). On the far end of the spectrum of possibilities is that $\operatorname{Tr} 1$ cells actually may play beneficial roles that are masked by the over-representation of their "natural cousins" within the tumor microenvironment. Perhaps the ratio between nTregs and $\operatorname{Tr} 1$ iTregs may be key to understanding their contribution to shaping the course of tumor progression. In support of this idea, ex vivo stimulated PBMCs of ovarian cancer patients who had better survival outcomes upon previous infusion with Th1-like CD4+ cells, contained higher fractions of both CD4+CD25+CD45RO+FoxP3+ and CD4+CD25-FoxP3- IL10 -producing cells compared to cells derived from short-term survivors (30). Importantly, the ratio of the Foxp3+ nTregs versus IL-10+ Tr 1 cells was touted to be key to better outcome as the one patient that remained cancer-free showed a dwindling pattern in the frequency of CD4+Foxp3+ cells while the $\operatorname{Tr} 1$ cell numbers steadily increased with each cycle of T-cell infusion and ex vivo PBMC stimulation. Could induced regulatory cells that present in the form of IL-10-producing $\operatorname{Tr} 1$ cells be beneficial in the context of tumor immunity? Perhaps some studies in the foreseeable future may specifically tackle this question. IL-10 being a cytokine that appears to play both inhibitory and immunostimulatory roles $(25,26,32,36)$, an anti-tumor immunity-boosting role for IL-10+ $\operatorname{Tr} 1$ cells is thus, not unimaginable and the above study certainly leaves room for such deduction. Consistent with this notion, IL10-producing CD4+ cells have been demonstrated to effect tumor rejection in a murine glioma model by augmenting CTL and NK cell response (32). Perhaps, "curative" outcome seen from a combination of standard cancer treatments and immune modulatory protocols favor an increase in a discrete, unobstructive, $\operatorname{Tr} 1$ cell population with a concomitant decrease in a tampering nTreg subset. At any rate, more studies are warranted to better understand how $\operatorname{Tr} 1$ cells shape the course of anti tumor immunity, and by extension, tumor progression. In addition, identification of reliable markers to pin-point categorically their existence in tumor mass and in circulation of cancer patients without a need to amplify them in vitro is necessary.

\section{DIFFERENTIATING NATURAL TREGS FROM INDUCED TREGS HELIOS}

Expression of Helios, a member of the Ikaros transcription factor family has been described to be a part of Treg genetic signature based on a number of gene array analysis $(37,38)$. In a recent report, essentially all thymic Treg cells were Helios + but only about $70 \%$ of the peripheral pool retained their expression (39). Furthermore, in vitro and in vivo-generated iTregs failed to express Helios. An argument was thus made that Helios expression may mark the bona fide nTregs of thymic origin (39). Building on this observation, studies in tumor-bearing mice and human cancers have also explored the composition of tumor-infiltrating Treg cells with respect to Helios expression (40-42). Treg cells from peripheral 
blood of renal cell carcinoma (RCC) patients were found to consist of a population that expressed Helios (40). In human ovarian carcinomas, CXCR3+ Treg cells were reported to be abundantly represented in the majority of tumor-Treg cells and they coexpress Helios (41). In another study that used a xenogeneic mouse model of malignant human brain tumor, it was demonstrated that majority of tumor-associated Treg cells expressed Helios, and their frequency decreased when tumor-bearing mice were thymectomized prior to tumor cell implantation (42). In all of these studies, the consensus was that the Treg cells within the tumors are most likely natural due to their expression of this transcription factor. On the contrary, it was reported that the vast majority of tumor-infiltrating Treg cells in a murine colon adenocarcinoma expressed low levels of Helios and the authors concluded that based on this phenotype, coupled with additional markers, these are likely to be iTregs (43). In the absence of any immune pathology in the colon however, it should be pointed out that colonic Treg cells may be predominantly thymus-derived nTreg cells as recently demonstrated (44). When weighed together, these observations only reinforce the possibility that the expression of Helios on tumor-infiltrating Treg cells may not necessarily be an indication that they are derivatives of nTreg cells. Further putting into question the reliability of Helios in resolving the dichotomy of " $i$ " versus " $n$ " Treg cells are some existing reports (45-47). Using polyclonal or antigen-specific stimulation methods to activate $\mathrm{T}$ cells derived from TCR-transgenic $\mathrm{Rag}^{-1-}$ mice (hence, no endogenous Tregs), Wraith and colleagues demonstrated that a substantial fraction of in vitro-generated iTregs expressed Helios under the latter stimulation condition (47). Another group also described transient expression of Helios on activated human and murine $\mathrm{T}$ conventional and Treg cells (45). Whether Helios positive versus negative Foxp3+ cells simply represent different versions of the same Treg group (i.e., $\mathrm{n}$ Tregs) is of particular interest given that the profile of iTreg cells generated in adoptively transferred lymphopenic mice based on gene expression analysis was found to be relatively similar to $n$ Treg cells from normal mice (48). As Treg cells encounter tumor-associated antigens (TAA), it remains a possibility that they become activated and upregulate Helios expression. In this context, expression of Helios simply is not sufficient to distinguish the origin of tumor-Tregs.

\section{NEUROPILIN-1}

Neuropilin-1 (Nrp-1), a type-1 transmembrane protein is yet another molecule that is being implicated in the iTreg versus nTreg identification issue $(43,49,50)$. Using microarray analysis, Haribhai and team demonstrated that iTreg cells induced in vitro under TGF- $\beta$ and IL-2 expressed very low levels of Nrp1 compared to nTregs cells (49). In an MBP-specific TCR-transgenic mouse model under Rag deficiency background, another report demonstrated the existence of Foxp3+ iTreg cells in peripheral compartments, which persisted even in athymic mice suggesting that they were extrathymically derived (50). These cells expressed low levels of Nrp-1. In a model of iTreg cell generation via mucosal routes, Lafaille and colleagues demonstrated that mucosal iTreg cells or iTreg cells generated in vivo under non-inflammatory conditions also express low levels of Nrp-1 unlike nTreg cells in which high expression levels were noted. Under inflammatory conditions however, iTreg cells upregulated its expression (43). In tumor settings, there is only scant data describing Nrp-1 expression in association with sub-phenotypes of Treg cells. In one report, there was a positive trend toward increased presence of a sizable fraction of Foxp3+ cells which exhibited low expression levels of Nrp-1 in the tumor tissue of tumor-bearing mice. In contrast, Nrp-1hi cells predominated in the spleen suggesting that the Nrp-lo phenotype may represent a population of iTreg cells induced locally within the tumor (43). Taken together, these studies allude to the possibility that Nrp-1 expression may be a good indicator for distinguishing between peripherally induced adaptive Treg cells and may be particularly suitable in deciphering the composition of tumor-infiltrating Foxp3+ Treg cells.

\section{OTHER MARKERS}

Worth mentioning are a myriad of cell surface molecules and receptors that have also been associated with tumor-infiltrating Treg cells (41, 51-56). Garpin (GARP; glycoprotein A repetitions predominant) was found in one study to be significantly higher on Foxp3+ Treg cells in hepatocellular carcinoma patients (55). Lymphocyte activation gene-3 (LAG-3), a CD4 homolog that binds MHC class II is yet another molecule that has been described to distinguish a unique sub-population of CD4+Foxp3+ Treg cells that expand at tumor sites (51). This study analyzed the frequency and phenotype of Foxp3+ cells in melanoma and colorectal cancer patients at different stages of disease and discovered that increased percentages of LAG-3-expressing Foxp3+ Treg cells preferentially expanded in the peripheral blood and tumor sites raising the notion that these cells represent a subset of tumor-iTreg cells (51). Other studies identified TNFR2, TIM-3, and ICOS as upregulated on Treg cells at tumor sites suggesting they may represent a distinct Treg cell subset that are generated specifically in response to TAA $(52-54,56)$. In a human melanoma study, for example, CD4+Foxp3+ Treg cells infiltrating tumor tissue not only displayed upregulated expression of ICOS but also exhibited a more potent suppressive activity compared to those derived from circulating blood cells (54). While these assessments were not particularly geared toward separating tumor-infiltrating Treg cells into natural or induced subset, it could be insightful if their expression patterns are considered in tandem with analysis focused at determining the composition of tumor-Treg cells with respect to their origin. (See Table 1 for a number of cancer studies in which some of these markers or TCR repertoire pattern were implicated in the suggested origin of tumor-infiltrating Treg cells.)

\section{nTREG VERSUS ITREG IN TUMORS; A FUNCTION OF ACTIVATION/DIFFERENTIATION STATUS?}

Perhaps, a healthy dose of objectivity is ideal in our trying to piece together the different phenotypes exhibited by Foxp3+ Treg cells in different tumors and finding a unifying phenotype that specifically identifies subsets. The increased expression of some of the afore-mentioned molecules upon $\mathrm{T}$ cell activation $(57,58)$ raises the possibility that the various unique phenotypes as observed in many tumor models and human cancers may simply represent an activation state and not an indication of a different cohort of iTreg cells generated from peripheral non-Treg cells. For instance, a recent study reported that the expression of GARP identifies 
Table 1 | Natural and induced Treg cells in cancer.

\begin{tabular}{|c|c|c|c|c|c|}
\hline Species & Cancer type/tumor model & Treg phenotype & Suggested origin & Origin indicator & Reference \\
\hline Human & Ovarian carcinoma & CD4+FOXP3+; CXCR3+, T-bet+ & Natural & Helios expression & (41) \\
\hline Human & Colon adenocarcinoma & CD4+FOXP3+; CCR4+CTLA-4hi & Unknown & & (89) \\
\hline Human & Ovarian cancer & CD4+FOXP3+; Helios+, CCR4 ${ }^{\text {lo }}$ & Unknown & & $(61)$ \\
\hline Mice/Rats & Colon carcinoma/melanoma & CD4+CD25+/Foxp3+ & Natural & Expansion via mDC-TGF- $\beta$ & $(18)$ \\
\hline Mice & Fibrosarcoma & CD4+Foxp3+ & Natural & $\begin{array}{l}\text { Distinct TCR repertoire versus } \\
\text { CD4+CD25- }\end{array}$ & $(17)$ \\
\hline Mice & Colon carcinoma & CD4+Foxp3+ & Induced & $\begin{array}{l}\text { Foxp3 induction in } \\
\text { CD4+CD25- }\end{array}$ & $(20)$ \\
\hline Mice & Renal cell carcinoma & CD4+CD25+/Foxp3+ & Induced & Foxp3 induction via TGF- $\beta$ & $(19)$ \\
\hline Human & Renal cell carcinoma & CD4+FOXP3+ & Natural & Helios expression & $(40)$ \\
\hline Mice, human & Glioblastoma & CD4+Foxp3+ & Natural & Helios expression & $(42)$ \\
\hline Mice & Colon adenocarcinoma & CD4+Foxp3+; Nrp-1 ${ }^{\text {lo }}$, Helios $^{\text {lo }}$ & Induced & Helios and Nrp-1 expression & $(43)$ \\
\hline Mice & Tumor cell line/melanoma & CD4+Foxp3+ & Natural & $\begin{array}{l}\text { Distinct TCR sequence versus } \\
\text { CD4+CD25- }\end{array}$ & $(70)$ \\
\hline Human & Hodgkin lymphoma & $\begin{array}{l}\text { CD4+IL-10+ Tr1 and } \\
\text { CD4+CD25+ }\end{array}$ & Unknown & & $(26)$ \\
\hline Human & Ovarian cancer & $\begin{array}{l}\text { CD4+CD25-FOXP3- IL-10+Tr1 } \\
\text { and CD4+CD25+Foxp3+ }\end{array}$ & Induced and natural & $\begin{array}{l}\text { IL-10 production or Foxp3 } \\
\text { status }\end{array}$ & (30) \\
\hline
\end{tabular}

activated human CD4+Foxp3+ Treg cells especially upon in vitro stimulation (58). Although very few studies have demonstrated the antigen specificity of tumor-infiltrating Treg cells (59, 60), one might speculate that the bulk of the Treg cells infiltrating the tumor have encountered and been activated by some TAA, hence are antigen-experienced. Therefore, it remains plausible that the different phenotypes as observed in different tumor models and human cancers is a reflection of their activation status and a factor of antigen repertoire to which the Treg cells are exposed in the tumor and/or draining lymph nodes. In sync with this notion, a recent study in late stage ovarian cancer patients noted a dominant population of Helios + activated Treg cells in disseminated tumors (61). Another issue is whether the expression of these molecules signals a terminal differentiation stage. We previously reported that in humans, CD45RA-Foxp3hi cells are activated and terminally differentiated (62). In a murine study, KLRG1-expressing Treg cells were identified and also deemed to be terminally differentiated (63). Thus, tumor-infiltrating Treg cells may well be derived from pre-existing pool of peripheral nTreg cells but exhibit unique phenotypic properties reflective of their activation status and/or differentiation stage as opposed to being generated from non-Treg precursors, hence induced.

Expanding on this issue, it has been said that tumor-infiltrating Treg cells appear to display an effector phenotype that likely emanates from chronic exposure to TAA (10, 64, 65). Could expression of an effector phenotype distinguish between nTregs from iTregs? This is unlikely given that both potentially co-inhabit the tumor and are subjected to similar antigenic cues. Cretney et al., opined that activated/effector Treg cells display unique phenotypic features that distinguishes them from naïve cells $(66,67)$. In one of their studies, they described a distinct population of Blimp-1-expressing Treg cells with an effector phenotype (67). Given that IL-2 and inflammatory signals was shown to facilitate their production, one might speculate that the prevalence of such inflammatory cytokines/signals in the tumor surroundings may favor the recruitment or generation of these functionally mature effector Treg cells. In this context, Blimp-1 could be useful to identify effector Tregs which are derived from the natural pool versus those induced from CD25- cells in situ. Perhaps, an evaluation of a plethora of activation-associated markers such as described by Cretney and colleagues may yield some clues as to which subset of tumor-infiltrating Treg cells are natural or induced regardless of their antigen experience.

At the genetic level, molecular analysis has revealed that while nTreg cells show a stable hypomethylation pattern at the Foxp3 locus, iTregs generated in vitro and in vivo are fickle, presenting with unstable Foxp3 expression with partial hypomethylation pattern $(68,69)$. Although both iTreg and nTreg in the tumor may be indistinguishable in terms of having an effector phenotype, assessing Foxp3 epigenetic modification patterns could be useful to differentiate nTregs from iTregs.

\section{TCR REPERTOIRE DIVERSITY AND ANTIGEN SPECIFICITY OF TUMOR-INFILTRATING TREG CELLS}

Currently, there is paucity of data addressing the issue of antigen specificity and TCR repertoire within tumor-associated Treg cells and how this information may define induced versus nTreg cells. The notion that Treg cells accumulating within tumors might be nTreg cells was presented by Gallimore's lab. In one of their studies as mentioned previously, they analyzed the TCR repertoires of Treg cells and $\mathrm{T}$ conventional cells within the tumor tissue and found that they were largely distinct concluding that based on this finding, tumor-Tregs are likely derivatives of nTregs (17). In another study using non-TCR-transgenic mice, immunoscopebased analysis of the TCR repertoire of tumor-infiltrating Treg cells and $\mathrm{T}$ effector cells revealed that each population exhibited a skewed and distinct repertoire indicative of clonal expansion, hinting that the tumor-infiltrating Tregs are likely a few clones 
that proliferate extensively in the tumor (70). Further analysis of CDR3 sequences revealed some public sequences that were unique to Treg cells obtained from multiple tumor tissues but had little overlap with $\mathrm{T}$ effector cells arguing against the possibility that the Treg cells were converted from T effector cells, although based on the limited scope of the work, such possibility still cannot be excluded.

Treg cells are selected with TCRs specific for self peptide: MHC constituents $(71,72)$ and many TAA are self antigens (73). Furthermore, Treg cells can recognize an array of tumorassociated immunogenic self antigens $(74,75)$. So, it is possible that tumor-infiltrating Treg cells exhibit unique TCR repertoire highly reactive against some of the TAA. Supporting this notion, a human-melanoma-infiltrating Treg clone specific for LAGE-1, a cancer/testis antigen that is expressed in many types of tumors was identified in a study (76). It should be reiterated here that the expression of cancer/testis antigens is normally restricted to male germ cells but not in adult somatic tissues. On that account, they are cancer tissue-specific self antigens. In another study, the same group reported the establishment of CD4+ Treg clones generated from tumor-infiltrating lymphocytes of cancer patients which were reactive against another tumor-derived ARTC1 peptide (77). In another unrelated study, NY-ESO-1 (New York esophageal squamous-cell carcinoma-1)-specific CD4+ T cells were generated from naïve $\mathrm{T}$ cell preparation upon Treg cell depletion suggesting that Treg cells, presumably an antigen-specific subset suppressed NY-ESO-1-specific T cell induction in cancer patients (78). Thus, circulating tumor-antigen-specific Treg cells exist at least in patients with certain cancers (79). While these studies suggest to a certain extent, the self specificity of tumor-infiltrating Treg cells, the issue of their origin was not addressed. How might iTreg cells and nTreg cells in the tumor differ with respect to their antigen specificity and repertoire? Answering this question requires a clear understanding of which of these two subsets predominates in specific cancers. Then, our efforts could expand to deciphering their peptide specificity, immunodominant epitopes of such peptides, and TCR diversity of Treg cells that may recognize them through combination of techniques including but not limited to cloning, proteomics, and spectratyping analysis.

\section{TUMOR-TREG CELL RECRUITMENT AND TRAFFICKING}

The recruitment of Treg cells (natural or induced) into tumors likely involves complex, multi-step processes that ultimately culminate in the high frequencies observed in many cancers. Perhaps, the expression of certain receptors may be key to unraveling some of these processes and sorting the suppressor cells. One potential candidate protein is Neuropilin-1 (Nrp-1), the expression of which was found to be low on in vivo-generated iTreg cells under noninflammatory conditions unlike nTreg cells which preferentially expressed this protein at high levels (43). In tumor-bearing mice, Nrp-1 expression on Treg cells was demonstrated to promote their recruitment to tumor site via tumor-derived VEGF gradient (80). Anecdotally, Nrp-1, the expression of which is very low in naïve T conventional cells is under Foxp 3 control as ectopic expression of Foxp 3 in these cells led to induction of Nrp-1 $(37,81)$. Given that TGF- $\beta$ can bind Nrp- 1 in addition to inducing Foxp 3 expression $(35,82)$, it remains plausible that TGF- $\beta$-induced Foxp $3+$ iTreg cells, armed with Foxp3-induced Nrp-1 expression, respond to further TGF- $\beta$ binding in a positive feedback loop, and ultimately become recruited across similar gradient as the nTreg cells.

Chemokine receptor pattern while largely unexplored, could be another critical aspect of tumor-affiliated Treg cells that could be useful in determining Tumor-Treg sub-groups. For example, in human ovarian carcinomas, selective accumulation of Treg cells expressing high levels of chemokine receptor CXCR3 was noted (41). Similarly, Treg cells that infiltrated colorectal tumor mass preferentially expressed CCR6 which appeared to promote their recruitment via tumor-associated macrophage production of CCL20 (83). In skin tumor-bearing mice, CCR5 was preferentially expressed on tumor-infiltrating Treg cells, which seemed to be recruited to the tumor via its ligands, CCL3, 4, and 5 that was produced by myeloid-derived suppressor cells (MDSCs) (84). Similarly, CCR5 signaling appeared to facilitate the recruitment of Treg cells to pancreatic adenocarcinoma (85). Other chemokine receptors implicated in Treg trafficking to tumor sites include CXCR4, which drives Treg cells toward tumor site via interactions with CXCL12 that is produced within the tumor microenvironment, as well as CCR8 and CCR10 (86-88). In the case of CCR10, hypoxia within ovarian tumor environment promotes the secretion of CCL28 by cancer cells which in turn enhances the recruitment of Foxp3+ Treg cells via CCR10 (87). Furthermore, in studies of oral squamous-cell carcinoma and colon adenocarcinoma, increased frequencies of tumor-associated CCR4hi cells were reported (89, 90). Consistent with this and other reports $(16,91,92)$, we have recently identified CCR4 to be highly expressed on the majority of tumor-infiltrating Treg cells in a human melanoma study (manuscript in preparation). Notably, their phenotype was unique and distinct from their counterparts in non-tumor-associated peripheral blood. Whether these Treg cells are peripherally recruited by tumor-derived factors such as CCL22, which is a chemokine that is widely produced by a number of tumors, and a ligand for CCR4 $(12,65)$ remains to be determined and is a subject of our ongoing investigations.

In contrast to our observations and that of others mentioned above, one report found that tumor-infiltrating Treg cells exhibited markedly reduced levels of CCR4 in HNSCC relative to circulating Tregs (61). One obvious explanation for variabilities between these studies is that differences in tumor type, infiltrating immune cells, and stage of disease likely impacts the phenotype of Treg cells prevalent within tumors at time of investigation. Despite the lack of any extrapolation from all these studies as to the natural or induced status of tumor-Treg cells, they bring to light, the notion that the tumor milieu likely shapes the composition of Treg cells present within it as different Treg cell subsets express different homing receptors based on the environmental cues to which they are subjected (93). Thus, different tumors may exhibit distinct Treg cell composition that reflects such properties. In this regard, evaluation of homing receptor expression pattern in various human cancers may thus shed more light to whether they are locally induced, or are expanded from a recruited natural population.

\section{INDUCED/ADAPTIVE TREG GENERATION IN TUMORS}

The mechanisms involved in de novo generation of adaptive Treg cells are still unclear. Several lines of evidence point to the 
suppressive cytokine milieu prevalent within the tumor environment as a major contributory factor (94). For instance, TGF- $\beta$ can induce iTreg cells and it is well established that several tumor lines utilized in murine tumor studies secrete TGF- $\beta$ (19, 95-97). Other tumor-derived soluble factors such as GM-CSF and VEGF may recruit or expand MDSCs which then secrete cytokines that could potentially induce Treg cells $(98,99)$. Additionally, tumorassociated macrophages or DCs may be instrumental in inducing Treg cells or recruiting discrete subsets of Treg cells with distinct phenotypes $(83,100)$.

Similar to the phenomenon of infectious tolerance (101), Treg cells may also directly enlist naïve $\mathrm{T}$ cells into the regulatory pool. In this regard, Treg cell production of IL-10 and TGF- $\beta$ $(102,103)$ may also modulate some naïve CD4+ T cells, converting them to cells with inhibitory function. Another possibility is an indirect effect via modulation of DCs. Treg cells via CTLA4 may keep DCs in an immature state by engaging CD80 and CD86 molecules on these antigen presenting cells (102). Such immature DCs may induce Foxp3 or Foxp+-like phenotype, in line with their demonstrated ability to efficiently induce iTreg cells in vivo (104). The modification of tumor-associated APCs is however not restricted to Treg effect alone. Other inhibitory agents produced by tumors such as IDO (105) may re-shape DCs to become tolerogenic and in turn promote induction of Foxp3+ Treg cells (106). Taken together, adaptive Treg cell generation may be promoted by tumor-related expression of key cytokines and soluble factors that have the potential to induce Foxp3+ cells from existing pool of tumor-infiltrating conventional CD4+ $\mathrm{T}$ cells or recruit discrete regulatory $\mathrm{CD} 4+\mathrm{T}$ cells from distal sites.

In a nutshell, it is evident that the generation of adaptive Treg cells is likely a complex phenomenon and multiple pathways may be involved (Figure 1). Adding to this complexity is the tumor itself: its properties such as cytokine and chemokine milieu, angiogenic capabilities, etc. may determine or shape the generation of these peripherally induced adaptive Treg cells.

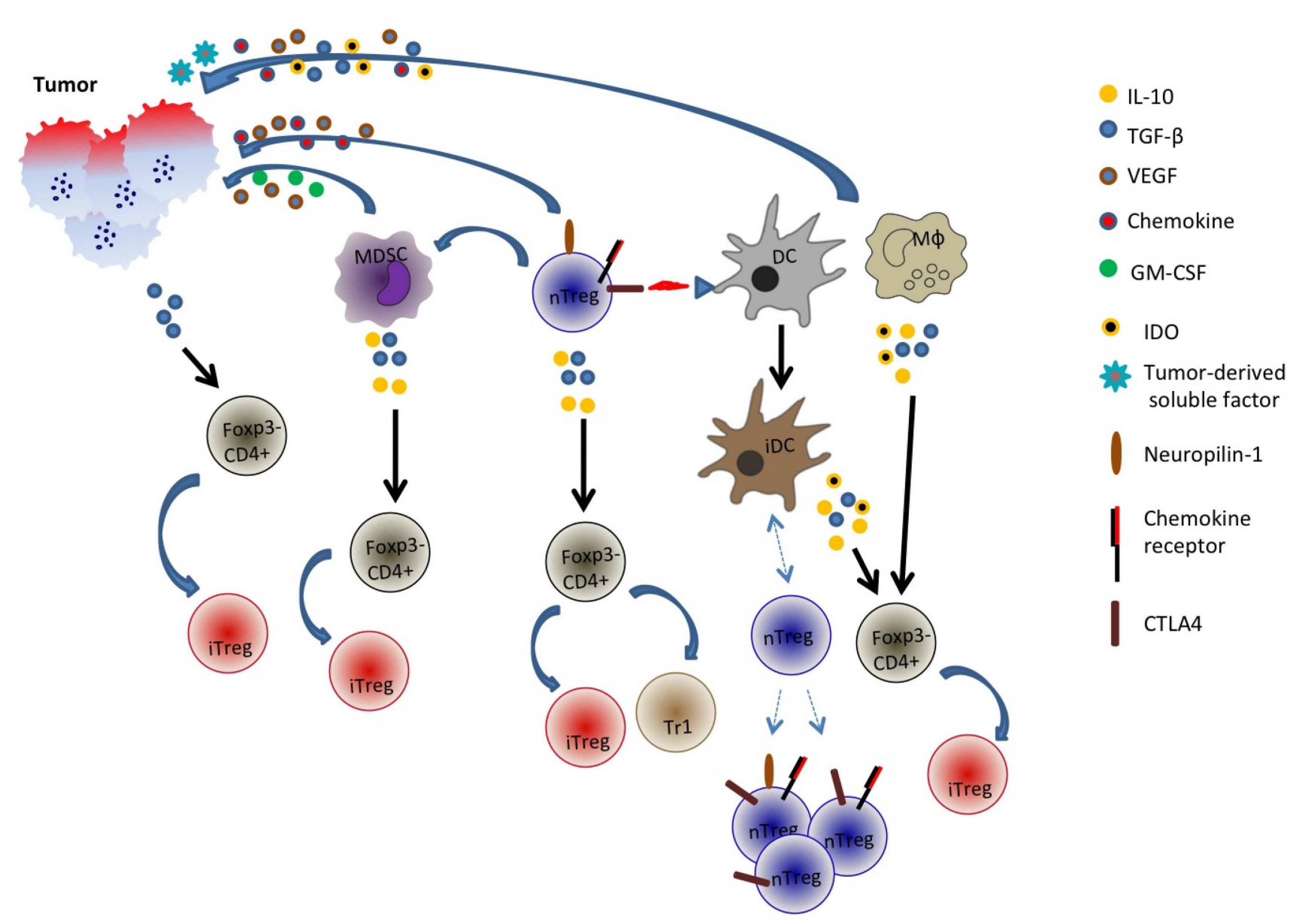

FIGURE 1 | Generation and recruitment of adaptive/induced Tregs in the tumor microenvironment. Tumor cells may secrete an array of cytokines and soluble factors that facilitate the induction of Foxp3 in Foxp3-cells or the recruitment of multiple cell types including natural Treg cells, myeloid-derived suppressor cells (MDSC), dendritic cells (DC), and macrophages. These cells in turn may secrete inhibitory and immune-suppressive factors such as TGF- $\beta$, IL-10, and indoleamine 2,3-dioxygenase (IDO) that could potentially convert some Foxp3- CD4+ cells into Foxp3+ cells. Additionally, tumor-derived factors or Treg interaction with DCs may promote generation of tolerogenic or immature DC (iDC) that recruit distinct populations of natural Tregs. nTreg is CD4+Foxp3+ cells while iTreg is CD4+Foxp3 variable. 


\section{Foxp3 STABILITY AS AN INDICATOR OF NATURAL VERSUS} INDUCED TREG CELLS IN TUMORS?

Addressing the issue of Foxp3 stability within tumor-associated Treg cells, a recent report evaluated tumor-resident Treg cells. Using reporter mice that bear melanoma, authors were able to differentiate between "ex" and "current" Foxp3+ Treg cells (64). In this study, it was found that majority of the tumor-Treg cells retain Foxp3 expression and only a minor population lost its expression providing evidence that Foxp3 expression even in an inflammatory environment as the tumor remained stable. Since iTregs only show a partial DNA hypomethylation pattern unlike nTregs $(68,69)$, indicating a transient opening up of the Foxp3 locus, they do not to stably express Foxp3 and may even likely lose its expression in the absence of signals that elicited Foxp3 induction. Extrapolating from this, it is tempting to conclude that majority of tumor-Treg cells are likely nTregs based on their Foxp3 stability and not iTregs as Foxp3 unstable Treg cells would otherwise constitute a sizable fraction of tumor-Tregs if they were induced from conventional $\mathrm{CD} 4+\mathrm{T}$ cells. Evaluations such as genetic profiling of Foxp3 locus thus may be useful in delineating what constituency Treg cells in different tumors belong to, i.e., the "i" or the " $n$ " family.

\section{FUNCTION OF NATURAL VERSUS INDUCED TREG CELLS}

Several questions linger as we attempt to understand the role of iTreg cells versus nTreg cells in tumor immunobiology: is the role of iTregs largely redundant when nTreg cells are present? If not, do they possess similar specificity and or play similar roles as their natural counterparts? Two studies, one in a colitis model, the other in Foxp3-deficient mice, which succumb to lymphoproliferative disease, demonstrated that full protection from disease was only achieved when both nTreg cells and iTreg cells were present, suggesting that the function of each Treg cell group is complementary $(49,107)$. As Lafaille and colleagues surmised, a division of labor between nTreg cells and iTreg cells seems a plausible arrangement as far as their functional roles in regulating immune responses (13). One might speculate that given their sheer dominance and omnipresence, nTreg cells share the greater bulk of curtailing $\mathrm{T}$ cell responses while adaptive Treg cell contribution is solicited as needed and differs on a case-by-case à la cancer-by-cancer model. Relating to this principle, a study described the accumulation of $\mathrm{nTreg}$ cells and iTreg cells in the tumor microenvironment, with the latter possessing TCR specificity for a defined antigen expressed by the tumor. Suppression by cognate-antigen-specific iTreg cells was restricted to $\mathrm{CD} 4+\mathrm{T}$ cells and occurred only within the local tumor environment while suppression of CD8+ T-cell response was independent of these tumor-antigen-specific iTreg cells (108). From this, one might deduce that iTreg cells evolve peripherally as in the tumor only to control some arms of the immune response while the nTreg cells control others.

In many colorectal cancer studies, the observation that increased Foxp3+ Treg cells correlate with good prognosis is particularly intriguing (109). An argument has been made that the Treg cells in this context may largely be involved in controlling potential inflammation that could ensue in response against the commensal bacteria present in the lower intestine if Tregs are absent (13). Given that GALT environment is permissive for induction of iTreg cells, it is tempting to speculate that the FOXP3+ Treg cells in colorectal cancer are mostly iTreg cells. To test this possibility, phenotypic characterization, TCR repertoire analysis, and FOXP3 methylation status of Treg cells in colorectal tumor tissues in parallel with solid tumors from sites not heavily associated with intestinal commensal bacteria could be a starting point.

Summarily, elucidating what environmental and molecular cues facilitate the generation of iTreg cells and the type of role they play particularly in various cancers would be eye-opening and may pave way for manipulating the immune system to prevent their generation in such context. At any rate, more studies are warranted to tease out who does what and to what degree is this division of labor shared.

\section{TREG THERAPY: TARGETING NATURAL AND ADAPTIVE/INDUCED TREGS}

To prime and/or boost anti-tumor immune response, selective removal or reduction of Treg cells have been carried out in a number of murine tumor studies (12). This depletion is generally achieved via the use of anti-CD25 mAb (PC61), anti-FR4 $\mathrm{mAb}$, and diphtheria toxin, the latter to DEREG mice (which express diphtheria toxin receptor under the control of Foxp3 promoter (110-114). In humans, daclizumab (anti-CD25) and denileukin diftitox (ONTAK, a fusion protein of diphtheria toxin and recombinant human IL-2) treatment has also shown some efficacy in some cancers, consequent to their Treg cell depletion effect although with varying degrees of success $(10,115)$. Cyclophosphamide, a chemotherapy agent that is a part of treatment regimen in some cancers is also known to target Treg cells by reducing their frequencies or function (116-119). In combination with tumor vaccination, all three agents were tested in melanoma patients in one study. Interestingly, only modest reduction in Treg cells (as determined by methylation status of FOXP3 intron 1 within Treg cells) was noted in the peripheral blood of patients in the treatment groups (120). In a recent clinical trial utilizing multiple tumor-associated peptides as a therapeutic vaccine for renal cell cancer, T-cell responses of treated patients were associated with better disease control and correlated with lower numbers of FOXP3+ Treg cells prior to vaccination. This revelation prompted the incorporation of cyclophosphamide to the vaccine regimen in subsequent study which demonstrated that reduced Treg cell numbers achieved by this approach further improved patients' immune responses to the tumor antigens and importantly, their overall survival (121). The caveat to all these studies is that the effect of these Treg cell depletion/reduction protocols have not been evaluated on Treg cell subsets and essentially no information is available on whether iTreg cells are more susceptible to these regimen than nTreg cells or vice versa. Thus, critical evaluation of the residual Treg cell fractions not targeted by these agents is warranted as they may represent an induced population with phenotypic changes that make them evade depletion regimen.

On the other hand, there is some evidence that nTreg cells are more resistant to oxidative stress or apoptosis than conventional $\mathrm{T}$ cells (122). Based on this, $n$ Treg cells, assuming they account for the majority of tumor-infiltrating Treg cells, may be the subset that is more resilient to therapeutic modalities aimed at eliminating tumor-Tregs. In this regard, multi-pronged approach combining 
multiple agents targeting " $\mathrm{i}$ " and " $\mathrm{n}$ " Tregs may be necessary to achieve efficient elimination. While their differential expression is yet to be assigned to either iTreg or nTregs cells, CCR4, PD1, and CTLA-4, which have been shown to be highly expressed on tumor-Treg cells (123) offer potential targets for treatment of cancers enriched in Treg cells with such phenotype. In alignment with this line of thinking, the combination of anti-CTLA-4 and anti-PD-1 antibody treatment in a mouse B16 melanoma study led to substantial reduction in Treg cells as well as myeloid cells with a concomitant increase in tumor-infiltrating effector T cells (124). Agonist antibody against Glucocorticoid-induced tumor necrosis factor receptor family-related protein (GITR), also expressed on Treg cells (125), is another treatment route that holds promise. In a murine model of melanoma, its administration promoted potent anti-tumor immune response (126). Similarly, in combination with anti-CTLA-4 antibody, anti-GITR administration evoked regression of established fibrosarcoma and colon carcinoma in other studies $(127,128)$. In either case, the positive outcomes were ascribed to anti-GITR antibody-mediated attenuation of Treg function or decreased intra-tumoral Treg cell accumulation, in addition to augmented CD+ T-cell effector response (126-128). For advanced melanoma, it is worth mentioning that administration of humanized anti-CTLA-4, ipilimumab improved survival of patients with metastatic melanoma in a clinical trial (129). In our recent investigations, we found that tumor-infiltrating $\mathrm{T}$ cells contained a higher frequency of effector Tregs with activated phenotypes compared with peripheral blood. Correspondingly, Tregs with a naive phenotype were barely detected in tumors while peripheral blood contained both naïve and effector Tregs. These tumor-infiltrating effector Tregs dominantly expressed CCR4, proposing CCR4 as a possible target for Treg control (manuscript in preparation).

The finding that human adaptive CD4+FOXP3+ Treg cells which express CD39, and CD73, and produce adenosine was described by Whiteside and co-workers (130). They demonstrated in vitro, the generation of iTreg cells with similar phenotype (except for FOXP3) in co-cultures simulating some of the features unique to the human cancer in which equivalent Treg cells were observed (131). They found that both adenosine and PGE2 produced by these iTreg cells co-operate in mounting strong suppressive function against autologous $\mathrm{T}$ effector cells. Thus, Whiteside proposed that targeting adaptive Treg cells by interfering with adenosinergic pathways and PGE2 production could be a viable therapeutic platform to disarm iTreg cells in human cancers (132).

Lastly, methods aimed at disrupting iTreg cell induction such as interfering with TFG- $\beta$ signaling in relevant tumors could be complementary approaches to vaccination. Using siRNA-mediated downregulation of TGF- $\beta$ production by B16 melanoma cells, this idea was explored by Mills and colleagues and they reported that tumor growth was hampered (133). This coincided with reduced tumor-Treg cell numbers although it was not clear as to whether this reduction affected iTreg cells as we might postulate based on experimental design.

Worth mentioning is the issue of Treg function at the interface of autoimmunity and cancer. The pivotal and positive role of Treg cells is exemplified in mice as well as IPEX patients in which impaired Foxp3 + Treg cell development culminates in wholesale breakdown of immune tolerance $(1,134,135)$. When placed in the context of tumors however, Treg suppressive function appears for the most part, to result in unfavorable prognosis. In fact, studies that portray Treg presence within the tumor in a bad light, i.e., inhibiting anti-tumor response outweigh those demonstrating they may have favorable contributions in cancer (10-12). In a recent report, melanoma patients who had better response following treatment with high dose IL-2 plus vaccine had higher Treg frequencies portraying a correlation between Tregs and better response against tumor (136). Thus, therapeutic strategies that are focused on Treg reduction in order to promote tumor clearance need to take this apparent duality in Treg function into account. More importantly is the effect such depletion may have on elevating a patient's risk for developing autoimmune conditions especially if systemic Treg depleting routes are utilized. In this regard, localized Treg reduction by intratumoral administration of Treg depleting agents which has shown efficacy at reducing tumor burden in mice (127) may offer a more favorable treatment platform without the inherent risk of the global Treg elimination assuming the tumor is accessible. Furthermore, since Treg cells in tumor environment appear to be of the effector Treg phenotype and may exhibit augmented suppressive activity when compared to those in circulation (64, 137-139), localized Treg modulation approach could be a viable option to target only a subset of highly suppressive, effector Treg cells based on specific molecules which they uniquely upregulate in response to tumor antigens. By so doing, the bulk of nTreg cells are left intact while only those "in action" are removed. This should be a feasible approach as we have recently tested the effect of antiCCR4 antibody on subsets of human Treg cells in melanoma patients and found it to efficiently eliminate a population of CCR4-expressing effector Tregs while sparing naïve Treg populations (manuscript in preparation). Until we have some evidence of the nature and extent of the contributions of nTregs and iTregs in various tumors, treading carefully on indiscriminate Treg depletion for cancer therapy however seems a reasonable proposition.

\section{PERSPECTIVES}

Different subsets of Treg cells may be committed to regulate specific arms of immune responses (140). Understanding the functional capabilities of both iTreg cells and nTreg cells will no doubt help in guiding future treatment platforms. A number of possibilities exist: their elimination from the tumor microenvironment, blocking their ability to produce a number of immunesuppressive/immune-altering molecules such as adenosine, PGE2, perforin, and granzyme $\mathrm{B}$, targeting anti-apoptotic pathways, disrupting their ability to proliferate and or persist in tumors, etc. The list is not conclusive as our understanding continues to expand about the nature of Treg cells that prevail in different cancer types. Thus, additional investigations are necessary to first determine whether the variabilities seen among different cancer studies with respect to phenotype associated with the tumor-Treg cells relate to their origin, i.e., are they natural or peripherally iTreg cells. From such information, we may be able to optimize Treg celltargeted approaches to reduce or eliminate not just a major subset 
that is prevalent within the tumor, but a minor subset that could contribute to hindering optimal therapeutic success in the settings where their presence is related to poor survival. To this end, designing antibodies against some of the molecules that appear to preferentially mark Treg cells infiltrating tumors may be a good investigational direction worth pursuing in our quest to treat cancers. It will be interesting to see whether such studies reveal information about the effect of treatment on subsets of Treg cells that are affected, and those that are resistant to modulation. At any rate, treatment modalities focused on elimination of Tregs

\section{REFERENCES}

1. Sakaguchi S, Sakaguchi N, Asano M, Itoh M, Toda M. Immunologic self-tolerance maintained by activated $T$ cells expressing IL2 receptor alpha-chains (CD25). Breakdown of a single mechanism of self-tolerance causes various autoimmune diseases. $J$ Immunol (1995) 155(3):115164.

2. Fontenot JD, Gavin MA, Rudensky AY. Foxp3 programs the development and function of CD4+CD25+ regulatory T cells. Nat Immunol (2003) 4(4):330-6. doi:10.1038/ni904

3. Khattri R, Cox T, Yasayko SA, Ramsdell F. An essential role for Scurfin in CD4+CD25+ T regulatory cells. Nat Immunol (2003) 4(4):337-42. doi:10.1038/ni909

4. Sakaguchi S, Yamaguchi $T$, Nomura T, Ono M. Regulatory $\mathrm{T}$ cells and immune tolerance. Cell (2008) 133(5):775-87. doi:10.1016/j.cell.2008.05.009

5. Curotto de Lafaille MA, Lafaille JJ. Natural and adaptive foxp3+ regulatory $\mathrm{T}$ cells: more of the same or a division of labor? Immunity (2009) 30(5):626-35. doi:10.1016/j.immuni

6. Bluestone JA, Abbas AK. Natural versus adaptive regulatory $\mathrm{T}$ cells. Nat Rev Immunol (2003) 3(3):253-7. doi:10.1038/nri1032

7. Roncarolo MG, Gregori S, Battaglia M, Bacchetta R, Fleischhauer K, Levings MK. Interleukin-10-secreting type 1 regulatory $\mathrm{T}$ cells in rodents and humans. Immunol Rev (2006) 212:28-50. doi:10.1111/j.01052896.2006.00420.x

8. Weiner HL, da Cunha AP, Quintana F, Wu H. Oral tolerance. Immunol Rev (2011) 241(1):241-59. doi:10.1111/j.1600-065X

9. Facciabene A, Motz GT, Coukos G. T-regulatory cells: key players in tumor immune escape and angiogenesis. Cancer Res (2012) 72(9):2162-71.
doi:10.1158/0008-5472.CAN11-3687

10. Whiteside TL, Schuler P, Schilling $B$. Induced and natural regulatory $\mathrm{T}$ cells in human cancer. Expert Opin Biol Ther (2012) 12(10):1383-97. doi:10. $1517 / 14712598.2012 .707184$

11. Elkord E, Alcantar-Orozco EM, Dovedi SJ, Tran DQ, Hawkins RE, Gilham DE. T regulatory cells in cancer: recent advances and therapeutic potential. Expert Opin Biol Ther (2010) 10(11):157386. doi:10.1517/14712598.2010. 529126

12. Nishikawa H, Sakaguchi S. Regulatory $\mathrm{T}$ cells in tumor immunity. Int J Cancer (2010) 127(4):75967.

13. Bilate AM, Lafaille JJ. Induced $\mathrm{CD} 4+$ Foxp3 + regulatory $\mathrm{T}$ cells in immune tolerance. Annu Rev Immunol (2012) 30:733-58. doi:10.1146/annurev-immunol020711-075043

14. Hori S, Nomura T, Sakaguchi S. Control of regulatory $\mathrm{T}$ cell development by the transcription factor Foxp3. Science (2003) 299(5609):1057-61. doi:10.1126/science.1079490

15. Wilke CM, Wu K, Zhao E, Wang G, Zou W. Prognostic significance of regulatory $\mathrm{T}$ cells in tumor. Int $\mathrm{J}$ Cancer (2010) 127(4):748-58. doi:10.1002/ijc.25464

16. Curiel TJ, Coukos G, Zou L, Alvarez X, Cheng P, Mottram P, et al. Specific recruitment of regulatory $\mathrm{T}$ cells in ovarian carcinoma fosters immune privilege and predicts reduced survival. Nat Med (2004) 10(9):9429. doi:10.1038/nm1093

17. Hindley JP, Ferreira C, Jones E, Lauder SN, Ladell K, Wynn $\mathrm{KK}$, et al. Analysis of the Tcell receptor repertoires of tumor-infiltrating conventional and regulatory $\mathrm{T}$ cells reveals no evidence for conversion in carcinogen-induced tumors. Cancer Res (2011) 71(3):736-46.

or disruption of their function to bolster anti-tumor immunity should take into account the differences between cancer types, the subset of the Tregs that predominate within the tumor, and their recruitment dynamics.

\section{ACKNOWLEDGMENTS}

This study was supported by Grants-in-Aid for Scientific Research (B) (No. 23300354, Hiroyoshi Nishikawa). Dennis O. Adeegbe is a research fellow of the Japan Society for the Promotion of Science.

\section{doi:10.1158/0008-5472.CAN- 10-1797}

18. Ghiringhelli F, Puig PE, Roux S, Parcellier A, Schmitt E, Solary E, et al. Tumor cells convert immature myeloid dendritic cells into TGFbeta-secreting cells inducing CD4+CD25+ regulatory $\mathrm{T}$ cell proliferation. J Exp Med (2005) 202(7):919-29. doi:10.1084/ jem.20050463

19. Liu VC, Wong LY, Jang T, Shah AH, Park I, Yang X, et al. Tumor evasion of the immune system by converting $\mathrm{CD} 4+\mathrm{CD} 25-\mathrm{T}$ cells into $\mathrm{CD} 4+\mathrm{CD} 25+\mathrm{T}$ regulatory cells: role of tumorderived TGF-beta. J Immunol (2007) 178(5):2883-92.

20. Valzasina B, Piconese S, Guiducci C, Colombo MP. Tumor-induced expansion of regulatory $\mathrm{T}$ cells by conversion of $\mathrm{CD} 4+\mathrm{CD} 25$ lymphocytes is thymus and proliferation independent. Cancer Res (2006) 66(8):4488-95. doi:10.1158/0008-5472.CAN05-4217

21. Chattopadhyay S, Mehrotra S, Chhabra A, Hegde U, Mukherji B, Chakraborty NG. Effect of CD4+CD25+ and CD4+CD25$\mathrm{T}$ regulatory cells on the generation of cytolytic $\mathrm{T}$ cell response to a self but human tumorassociated epitope in vitro. $J$ Immunol (2006) 176(2):984-90.

22. Kohm AP, McMahon JS, Podojil JR, Begolka WS, DeGutes M, Kasprowicz DJ, et al. Cutting Edge: anti-CD25 monoclonal antibody injection results in the functional inactivation, not depletion, of CD4+CD25+ $\mathrm{T}$ regulatory cells. J Immunol (2006) 176(6): 3301-5.

23. Gomella LG, Sargent ER, Wade TP, Anglard P, Linehan WM, Kasid A. Expression of transforming growth factor alpha in normal human adult kidney and enhanced expression of transforming growth factors alpha and beta 1 in renal cell carcinoma. Cancer Res (1989) 49(24 Pt 1):6972-5.

24. Zhou G, Levitsky HI. Natural regulatory $\mathrm{T}$ cells and de novoinduced regulatory $\mathrm{T}$ cells contribute independently to tumorspecific tolerance. J Immunol (2007) 178(4):2155-62.

25. Seo N, Hayakawa S, Takigawa M, Tokura Y. Interleukin-10 expressed at early tumour sites induces subsequent generation of $\mathrm{CD} 4(+)$ T-regulatory cells and systemic collapse of antitumour immunity. Immunology (2001) 103(4): 449-57. doi:10.1046/j.13652567.2001.01279.x

26. Marshall NA, Christie LE, Munro LR, Culligan DJ, Johnston PW, Barker RN, et al. Immunosuppressive regulatory $\mathrm{T}$ cells are abundant in the reactive lymphocytes of Hodgkin lymphoma. Blood (2004) 103(5):1755-62. doi:10.1182/blood-2003-072594

27. Akasaki Y, Liu G, Chung $\mathrm{NH}$, Ehtesham M, Black $\mathrm{KL}$, Yu JS. Induction of a $\mathrm{CD} 4+\mathrm{T}$ regulatory type 1 response by cyclooxygenase2-overexpressing glioma. $J$ Immunol (2004) 173(7):4352-9.

28. Bergmann C, Strauss L, Wang Y, Szczepanski MJ, Lang S, Johnson JT, et al. T regulatory type 1 cells in squamous cell carcinoma of the head and neck: mechanisms of suppression and expansion in advanced disease. Clin Cancer Res (2008) 14(12):370615. doi:10.1158/1078-0432.CCR07-5126

29. Bergmann C, Strauss L, Zeidler R, Lang S, Whiteside TL. Expansion of human $\mathrm{T}$ regulatory type 1 cells in the microenvironment of cyclooxygenase 2 overexpressing head and neck squamous cell carcinoma. Cancer Res (2007) 67(18):8865-73. doi:10.1158/0008-5472.CAN07-0767 
30. Dobrzanski MJ, Rewers-Felkins KA, Samad KA, Quinlin IS, Phillips CA, Robinson W, et al. Immunotherapy with IL-10and IFN-gamma-producing CD4 effector cells modulate "Natural" and "Inducible" CD4 Treg cell subpopulation levels: observations in four cases of patients with ovarian cancer. Cancer Immunol Immunother (2012) 61(6): 839-54. doi:10.1007/s00262011-1128-x

31. Bergmann C, Strauss L, Zeidler R, Lang S, Whiteside TL. Expansion and characteristics of human $\mathrm{T}$ regulatory type 1 cells in co-cultures simulating tumor microenvironment. Cancer Immunol Immunother (2007) 56(9):1429-42. doi:10. 1007/s00262-007-0280-9

32. Segal BM, Glass DD, Shevach EM. Cutting Edge: IL-10producing $\mathrm{CD} 4+\mathrm{T}$ cells mediate tumor rejection. I Immunol (2002) 168(1):1-4.

33. Vieira PL, Christensen JR, Minaee S, O’Neill EJ, Barrat FJ, Boonstra A, et al. IL-10-secreting regulatory $\mathrm{T}$ cells do not express Foxp3 but have comparable regulatory function to naturally occurring CD4+CD25+ regulatory T cells. J Immunol (2004) 172(10):5986-93.

34. Tran DQ, Ramsey H, Shevach EM. Induction of FOXP3 expression in naive human CD4+FOXP3 $\mathrm{T}$ cells by T-cell receptor stimulation is transforming growth factor-beta dependent but does not confer a regulatory phenotype. Blood (2007) 110(8):2983-90. doi:10.1182/blood-2007-06094656

35. Zou W. Regulatory $\mathrm{T}$ cells, tumour immunity and immunotherapy. Nat Rev Immunol (2006) 6(4):295-307. doi:10.1038/nril806

36. Mocellin S, Marincola FM, Young HA. Interleukin-10 and the immune response against cancer: a counterpoint. J Leukoc Biol (2005) 78(5):1043-51. doi:10.1189/jlb.0705358

37. Hill JA, Feuerer M, Tash K, Haxhinasto S, Perez J, Melamed R, et al. Foxp3 transcription-factor-dependent and -independent regulation of the regulatory $\mathrm{T}$ cell transcriptional signature. Immunity (2007) 27(5):786-800. doi:10. 1016/j.immuni.2007.09.010
38. Sugimoto N, Oida T, Hirota $K$, Nakamura K, Nomura $T$, Uchiyama T, et al. Foxp3dependent and -independent molecules specific for $\mathrm{CD} 25+\mathrm{CD} 4+$ natural regulatory $\mathrm{T}$ cells revealed by DNA microarray analysis. Int Immunol (2006) 18(8):1197-209. doi:10.1093/intimm/dxl060

39. Thornton AM, Korty PE, Tran DQ, Wohlfert EA, Murray PE, Belkaid Y, et al. Expression of Helios, an Ikaros transcription factor family member, differentiates thymic-derived from peripherally induced Foxp3+ regulatory cells. J Immunol (2010) 184(7):3433-41. doi:10.4049/jimmunol.0904028

40. Elkord E, Sharma S, Burt DJ, Hawkins RE. Expanded subpopulation of FoxP3 $+\mathrm{T}$ regulatory cells in renal cell carcinoma co-express Helios, indicating they could be derived from natural but not induced Tregs. Clin Immunol. (2011) 140(3):218-22. doi:10.1016/ j.clim.2011.04.014

41. Redjimi N, Raffin C, Raimbaud I, Pignon P, Matsuzaki J, Odunsi $\mathrm{K}$, et al. $\mathrm{CXCR} 3+\mathrm{T}$ regulatory cells selectively accumulate in human ovarian carcinomas to limit type I immunity. Cancer Res (2012) 72(17):4351-60. doi:10.1158/0008-5472.CAN12-0579

42. Wainwright DA, Sengupta S, Han Y, Lesniak MS. Thymusderived rather than tumorinduced regulatory $\mathrm{T}$ cells predominate in brain tumors. Neuro Oncol (2011) 13(12):1308-23. doi:10.1093/neuonc/nor134

43. Weiss JM, Bilate AM, Gobert M, Ding Y, Curotto de Lafaille MA, Parkhurst CN, et al. Neuropilin 1 is expressed on thymusderived natural regulatory $\mathrm{T}$ cells, but not mucosa-generated induced Foxp3 $+\mathrm{T}$ reg cells. J Exp Med (2012) 209(10):172342. doi:10.1084/jem.20120914

44. Cebula A, Seweryn M, Rempala GA, Pabla SS, McIndoe RA, Denning TL, et al. Thymusderived regulatory $\mathrm{T}$ cells contribute to tolerance to commensal microbiota. Nature (2013) 497(7448):258-62. doi:10.1038/nature12079

45. Akimova $\mathrm{T}$, Beier UH, Wang L, Levine MH, Hancock WW. Helios expression is a marker of $\mathrm{T}$ cell activation and proliferation. PLOS ONE (2011) 6(8):e24226. doi:10.1371/ journal.pone.0024226

46. Gottschalk RA, Corse E, Allison JP. Expression of Helios in peripherally induced Foxp3+ regulatory $\mathrm{T}$ cells. $J$ Immunol (2012) 188(3):976-80. doi:10.4049/jimmunol.1102964

47. Verhagen J, Wraith DC. Comment on "Expression of Helios, an Ikaros transcription factor family member, differentiates thymicderived from peripherally induced Foxp3+ $\mathrm{T}$ regulatory cells". Journal of immunology (2010) 185(12):7129. doi:10.4049/jimmunol.1090105 author reply 30 .

48. Feuerer M, Hill JA, Kretschmer $\mathrm{K}$, von Boehmer $\mathrm{H}$, Mathis D, Benoist C. Genomic definition of multiple ex vivo regulatory $\mathrm{T}$ cell subphenotypes. Proc Natl Acad Sci U $S$ A (2010) 107(13):5919-24. doi:10.1073/pnas.1002006107

49. Haribhai D, Lin W, Edwards B, Ziegelbauer J, Salzman NH, Carlson MR, et al. A central role for induced regulatory $\mathrm{T}$ cells in tolerance induction in experimental colitis. $J$ Immunol (2009) 182(6):3461-8. doi:10.4049/jimmunol.0802535

50. Yadav M, Louvet C, Davini D, Gardner JM, Martinez-Llordella M, Bailey-Bucktrout S, et al. Neuropilin-1 distinguishes natural and inducible regulatory $\mathrm{T}$ cells among regulatory $\mathrm{T}$ cell subsets in vivo. $J$ Exp Med (2012) 209(10):1713-22. doi:10.1084/jem.20120822

51. Camisaschi C, Casati C, Rini F, Perego M, De Filippo A, Triebel F, et al. LAG-3 expression defines a subset of CD4(+) CD25(high)Foxp3(+) regulatory $\mathrm{T}$ cells that are expanded at tumor sites. J Immunol (2010) 184(11):6545-51. doi:10. 4049/jimmunol.0903879

52. Chen X, Subleski JJ, Kopf H, Howard OM, Mannel DN Oppenheim JJ. Cutting edge: expression of TNFR2 defines a maximally suppressive subset of mouse CD4+CD25+FoxP3+ $\mathrm{T}$ regulatory cells: applicability to tumor-infiltrating $\mathrm{T}$ regulatory cells. J Immunol (2008) 180(10):6467-71.

53. Gao X, Zhu Y, Li G, Huang $H$, Zhang $G$, Wang $F$, et al. TIM-3 expression characterizes regulatory $\mathrm{T}$ cells in tumor tissues and is associated with lung cancer progression. PLoS ONE (2012) 7(2):e30676. doi:10. 1371/journal.pone.0030676

54. Strauss L, Bergmann C, Szczepanski MJ, Lang S, Kirkwood JM, Whiteside TL. Expression of ICOS on human melanoma-infiltrating CD4+CD25highFoxp3+ $\mathrm{T}$ regulatory cells: implications and impact on tumor-mediated immune suppression. J Immunol (2008) 180(5):2967-80.

55. Suresh KG, Lugade AA, Miller A, Iyer R, Thanavala Y. Higher frequencies of GARP+ CTLA$4+$ Foxp3 $+\mathrm{T}$ regulatory cells and myeloid-derived suppressor cells in hepatocellular carcinoma patients are associated with impaired $\mathrm{T}$ cell functionality. Cancer Res (2013) 73(8):2435-44. doi:10.1158/ 0008-5472.CAN-12-3381

56. Yan J, Zhang Y, Zhang JP, Liang J, Li L, Zheng L. Tim3 expression defines regulatory T cells in human tumors. PLoS ONE (2013) 8(3):e58006. doi:10. 1371/journal.pone.0058006

57. Hastings WD, Anderson DE, Kassam N, Koguchi K, Greenfield EA, Kent SC, et al. TIM-3 is expressed on activated human CD4+ $\mathrm{T}$ cells and regulates Th1 and Th17 cytokines. Eur J Immunol (2009) 39(9):2492501. doi:10.1002/eji.200939274

58. Wang R, Kozhaya L, Mercer F, Khaitan A, Fujii H, Unutmaz D. Expression of GARP selectively identifies activated human FOXP3+ regulatory T cells. Proc Natl Acad Sci U S A (2009) 106(32):13439-44.

59. Bonertz A, Weitz J, Pietsch DH, Rahbari NN, Schlude C, Ge Y, et al. Antigen-specific Tregs control $\mathrm{T}$ cell responses against a limited repertoire of tumor antigens in patients with colorectal carcinoma. J Clin Invest (2009) 119(11):3311-21.

60. Voo KS, Peng G, Guo Z, Fu T, Li Y, Frappier L, et al. Functional characterization of EBV-encoded nuclear antigen 1specific CD4+ helper and regulatory $\mathrm{T}$ cells elicited by in vitro peptide stimulation. Cancer Res (2005) 65(4):1577-86. doi:10.11 58/0008-5472.CAN-04-2552

61. Fialova A, Partlova S, Sojka L, Hromadkova H, Brtnicky T, Fucikova J, et al. Dynamics of Tcell infiltration during the course of ovarian cancer: the gradual shift from a Th17 effector cell 
response to a predominant infiltration by regulatory T-cells. Int J Cancer (2013) 132(5):1070-9. doi:10.1002/ijc.27759

62. Miyara M, Yoshioka Y, Kitoh A, Shima T, Wing K, Niwa A, et al. Functional delineation and differentiation dynamics of human CD4+ $\mathrm{T}$ cells expressing the FoxP3 transcription factor. Immunity (2009) 30(6):899-911. doi:10. 1016/j.immuni.2009.03.019

63. Cheng G, Yuan X, Tsai MS, Podack ER, Yu A, Malek TR. IL-2 receptor signaling is essential for the development of Klrgl+ terminally differentiated $\mathrm{T}$ regulatory cells. J Immunol (2012) 189(4):1780-91. doi:10.4049/jimmunol.1103768

64. Wang $\mathrm{C}$, Lee JH, Kim $\mathrm{CH}$. Optimal population of FoxP3+ $\mathrm{T}$ cells in tumors requires an antigen priming-dependent trafficking receptor switch. PLoS ONE (2012) 7(1):e30793. doi:10. 1371/journal.pone.0030793

65. Tanchot C, Terme M, Pere $\mathrm{H}$, Tran T, Benhamouda N, Strioga $\mathrm{M}$, et al. Tumor-infiltrating regulatory $\mathrm{T}$ cells: phenotype, role, mechanism of expansion in situ and clinical significance. Cancer Microenviron (2012):doi:10.1007/s12307-0120122-y

66. Cretney E, Kallies A, Nutt SL. Differentiation and function of Foxp3(+) effector regulatory $\mathrm{T}$ cells. Trends Immunol (2013) 34(2):74-80. doi:10.1016/j.it.2012.11.002

67. Cretney E, Xin A, Shi W, Minnich M, Masson F, Miasari M, et al. The transcription factors Blimp-1 and IRF4 jointly control the differentiation and function of effector regulatory T cells. Nat Immunol (2011) 12(4):304-11. doi:10.1038/ni.2006

68. Floess S, Freyer J, Siewert C, Baron U, Olek S, Polansky J, et al. Epigenetic control of the foxp3 locus in regulatory $\mathrm{T}$ cells. PLoS Biol (2007) 5(2):e38. doi:10.1371/journal.pbio.0050038

69. Ohkura N, Hamaguchi $M$, Morikawa $H$, Sugimura $K$, Tanaka A, Ito $\mathrm{Y}$, et al. $\mathrm{T}$ cell receptor stimulation-induced epigenetic changes and Foxp3 expression are independent and complementary events required for Treg cell development. Immunity (2012) 37(5):785-99. doi:10.1016/ j.immuni.2012.09.010
70. Sainz-Perez A, Lim A, Lemercier B, Leclerc C. The T-cell receptor repertoire of tumor-infiltrating regulatory $\mathrm{T}$ lymphocytes is skewed toward public sequences. Cancer Res (2012) 72(14):3557-69. doi:10.1158/0008-5472.CAN12-0277

71. Jordan MS, Boesteanu A, Reed AJ, Petrone AL, Holenbeck AE, Lerman MA, et al. Thymic selection of $\mathrm{CD} 4+\mathrm{CD} 25+$ regulatory $\mathrm{T}$ cells induced by an agonist selfpeptide. Nat Immunol (2001) 2(4):301-6. doi:10.1038/86302

72. Hsieh CS, Lee HM, Lio CW. Selection of regulatory $\mathrm{T}$ cells in the thymus. Nat Rev Immunol (2012) 12(3):157-67.

73. Khong HT, Restifo NP. Natural selection of tumor variants in the generation of "tumor escape" phenotypes. Nat Immunol (2002) 3(11):999-1005 doi:10.1038/ni1102-999

74. Nishikawa $H$, Kato $T$, Tanida K, Hiasa A, Tawara I, Ikeda $\mathrm{H}$, et al. $\mathrm{CD} 4+\mathrm{CD} 25+\mathrm{T}$ cells responding to serologically defined autoantigens suppress antitumor immune responses. Proc Natl Acad Sci U S A (2003) 100(19):10902-6. doi:10.1073/pnas.1834479100

75. Nishikawa H, Kato T, Tawara I, Saito K, Ikeda H, Kuribayashi K, et al. Definition of target antigens for naturally occurring CD4(+) CD25(+) regulatory $\mathrm{T}$ cells. $J$ Exp Med (2005) 201(5):681-6. doi:10.1084/jem.20041959

76. Wang HY, Lee DA, Peng G, Guo Z, Li Y, Kiniwa Y, et al. Tumorspecific human $\mathrm{CD} 4+$ regulatory $\mathrm{T}$ cells and their ligands: implications for immunotherapy. Immunity (2004) 20(1):10718 doi:10.1016/S10747613(03)00359-5

77. Wang HY, Peng G, Guo Z, Shevach EM, Wang RF. Recognition of a new ARTC1 peptide ligand uniquely expressed in tumor cells by antigen-specific CD4+ regulatory T cells. J Immunol (2005) 174(5):2661-70.

78. Nishikawa $H$, Jager E, Ritter G, Old LJ, Gnjatic S. CD4+ CD25+ regulatory $\mathrm{T}$ cells control the induction of antigenspecific CD4+ helper $\mathrm{T}$ cell responses in cancer patients. Blood (2005) 106(3):1008-11. doi:10.1182/blood-2005-020607

79. Vence L, Palucka AK, Fay JW, Ito T, Liu YJ, Banchereau
J, et al. Circulating tumor antigen-specific regulatory $\mathrm{T}$ cells in patients with metastatic melanoma. Proc Natl Acad Sci U S A (2007) 104(52):20884-9. doi:10.1073/pnas.0710557105

80. Hansen W, Hutzler M, Abel S, Alter C, Stockmann C, Kliche S, et al. Neuropilin 1 deficiency on CD4+Foxp3+ regulatory $\mathrm{T}$ cells impairs mouse melanoma growth. J Exp Med (2012) 209(11):2001-16. doi:10.1084/jem.20111497

81. Bruder D, Probst-Kepper M, Westendorf AM, Geffers R, Beissert S, Loser $\mathrm{K}$, et al. Neuropilin-1: a surface marker of regulatory $\mathrm{T}$ cells. Eur J Immunol (2004) 34(3):623-30. doi:10.1002/eji.200324799

82. Glinka Y, Prud'homme GJ Neuropilin-1 is a receptor for transforming growth factor beta-1, activates its latent form, and promotes regulatory $\mathrm{T}$ cell activity. J Leukoc Biol (2008) 84(1):302-10. doi:10.1189/jlb.0208090

83. Liu J, Zhang N, Li Q, Zhang W, Ke F, Leng Q, et al. Tumorassociated macrophages recruit CCR6+ regulatory $\mathrm{T}$ cells and promote the development of colorectal cancer via enhancing CCL20 production in mice. PLoS ONE (2011) 6(4):e19495. doi:10. 1371/journal.pone.0019495

84. Schlecker E, Stojanovic A, Eisen C, Quack C, Falk CS, Umansky $\mathrm{V}$, et al. Tumor-infiltrating monocytic myeloid-derived suppressor cells mediate CCR5dependent recruitment of regulatory $\mathrm{T}$ cells favoring tumor growth. J Immunol (2012) 189(12):5602-11. doi:10.4049/jimmunol.1201018

85. Tan MC, Goedegebuure PS, Belt BA, Flaherty B, Sankpal N, Gillanders WE, et al. Disruption of CCR5-dependent homing of regulatory $\mathrm{T}$ cells inhibits tumor growth in a murine model of pancreatic cancer. J Immunol (2009) 182(3):1746-55.

86. Wei S, Kryczek I, Edwards RP, Zou L, Szeliga W, Banerjee $M$, et al. Interleukin-2 administration alters the CD4+FOXP3+ T-cell pool and tumor trafficking in patients with ovarian carcinoma. Cancer Res (2007) 67(15):7487-94. doi:10.1158/0008-5472.CAN07-0565

87. Facciabene A, Peng X, Hagemann IS, Balint K, Barchetti A, Wang
LP, et al. Tumour hypoxia promotes tolerance and angiogenesis via CCL28 and T(reg) cells. Nature (2011) 475(7355):22630. doi:10.1038/nature10169

88. Jaafar F, Righi E, Lindstrom V, Linton C, Nohadani M, Van Noorden S, et al. Correlation of CXCL12 expression and FoxP3 + cell infiltration with human papillomavirus infection and clinicopathological progression of cervical cancer. Am J Pathol (2009) 175(4):1525-35. doi:10.2353/ajpath.2009.090295

89. Svensson H, Olofsson V, Lundin S, Yakkala C, Bjorck $\mathrm{S}$, Borjesson L, et al. Accumulation of CCR4(+)CTLA-4 FOXP3(+)CD25(hi) regulatory $\mathrm{T}$ cells in colon adenocarcinomas correlate to reduced activation of conventional $\mathrm{T}$ cells. PLoS ONE (2012) 7(2):e30695. doi:10. 1371/journal.pone.0030695

90. Watanabe Y, Katou F, Ohtani H, Nakayama T, Yoshie O, Hashimoto K. Tumorinfiltrating lymphocytes, particularly the balance between $\mathrm{CD} 8(+) \quad \mathrm{T}$ cells and $\operatorname{CCR} 4(+)$ regulatory $\mathrm{T}$ cells, affect the survival of patients with oral squamous cell carcinoma. Oral Surg Oral Med Oral Pathol Oral Radiol Endod (2010) 109(5):744-52. doi:10.1016/j.tripleo.2009.12.015

91. Gobert M, Treilleux I, BendrissVermare $\mathrm{N}$, Bachelot $\mathrm{T}$, Goddard-Leon S, Arfi V, et al. Regulatory $\mathrm{T}$ cells recruited through CCL22/CCR4 are selectively activated in lymphoid infiltrates surrounding primary breast tumors and lead to an adverse clinical outcome. Cancer Res (2009) 69(5):2000-9. doi:10.1158/0008-5472.CAN08-2360

92. Ishida $\mathrm{T}$, Ishii $\mathrm{T}$, Inagaki $\mathrm{A}$ Yano $\mathrm{H}$, Komatsu $\mathrm{H}$, Iida $\mathrm{S}$, et al. Specific recruitment of CC chemokine receptor 4-positive regulatory $\mathrm{T}$ cells in Hodgkin lymphoma fosters immune privilege. Cancer Res (2006) 66(11):5716-22. doi:10.1158/0008-5472.CAN06-0261

93. Campbell DJ, Koch MA. Phenotypical and functional specialization of FOXP3+ regulatory $\mathrm{T}$ cells. Nat Rev Immunol (2011) 11(2):119-30. doi:10.1038/nri2916

94. Whiteside TL. What are regulatory $\mathrm{T}$ cells (Treg) regulating in 
cancer and why? Semin Cancer Biol (2012) 22(4):327-34. doi:10. 1016/j.semcancer.2012.03.004

95. Chen W, Jin W, Hardegen N, Lei KJ, Li L, Marinos N, et al. Conversion of peripheral CD4+CD25naive $\mathrm{T}$ cells to $\mathrm{CD} 4+\mathrm{CD} 25+$ regulatory $\mathrm{T}$ cells by TGF-beta induction of transcription factor Foxp3. J Exp Med (2003) 198(12):1875-86. doi:10.1084/ jem.20030152

96. Chen W, Konkel JE. TGFbeta and 'adaptive' Foxp3(+) regulatory $\mathrm{T}$ cells. $J \mathrm{Mol}$ Cell Biol (2010) 2(1):30-6. doi:10.1093/jmcb/mjp004

97. Fantini MC, Becker C, Monteleone G, Pallone F, Galle PR, Neurath MF. Cutting edge: TGFbeta induces a regulatory phenotype in CD4+CD25- $\mathrm{T}$ cells through Foxp3 induction and down-regulation of Smad7. J Immunol (2004) 172(9):514953.

98. Gabrilovich DI, Nagaraj S. Myeloid-derived suppressor cells as regulators of the immune system. Nat Rev Immunol (2009) 9(3):162-74. doi:10.1038/nri2506

99. Huang B, Pan PY, Li Q, Sato AI, Levy DE, Bromberg J, et al. Gr-1+CD115+ immature myeloid suppressor cells mediate the development of tumor-induced $\mathrm{T}$ regulatory cells and T-cell anergy in tumor-bearing host. Cancer Res (2006) 66(2):1123-31. doi:10.1158/0008-5472.CAN05-1299

100. Ramos RN, Chin LS, Dos Santos AP, Bergami-Santos PC, Laginha F, Barbuto JA. Monocyte-derived dendritic cells from breast cancer patients are biased to induce CD4+CD25+Foxp3+ regulatory $\mathrm{T}$ cells. $J$ Leukoc Biol (2012) 92(3):673-82. doi:10.1189/jlb.0112048

101. Kendal AR, Waldmann $H$. Infectious tolerance: therapeutic potential. Curr Opin Immunol (2010) 22(5):560-5. doi:10.1016/j.coi

102. Yamaguchi T, Wing JB, Sakaguchi S. Two modes of immune suppression by Foxp3(+) regulatory $\mathrm{T}$ cells under inflammatory or noninflammatory conditions. Semin Immunol (2011) 23(6):424-30. doi:10.1016/j.smim

103. Strauss L, Bergmann C, Szczepanski M, Gooding W, Johnson JT, Whiteside
TL. A unique subset of CD4+CD25highFoxp3+ T cells secreting interleukin-10 and transforming growth factorbetal mediates suppression in the tumor microenvironment. Clin Cancer Res (2007) 13(15 Pt 1):4345-54. doi:10.1158/10780432.CCR-07-0472

104. Dumitriu IE, Dunbar DR, Howie SE, Sethi T, Gregory CD. Human dendritic cells produce TGF-beta 1 under the influence of lung carcinoma cells and prime the differentiation of CD4+CD25+Foxp3+ regulatory $\mathrm{T}$ cells. J Immunol (2009) 182(5):2795-807. doi:10.4049/jimmunol.0712671

105. Uyttenhove C, Pilotte L, Theate I, Stroobant V, Colau D, Parmentier N, et al. Evidence for a tumoral immune resistance mechanism based on tryptophan degradation by indoleamine 2,3-dioxygenase. Nat Med (2003) 9(10):1269-74. doi:10.1038/nm934

106. Brenk M, Scheler M, Koch S, Neumann J, Takikawa O, Hacker $\mathrm{G}$, et al. Tryptophan deprivation induces inhibitory receptors ILT3 and ILT4 on dendritic cells favoring the induction of human $\mathrm{CD} 4+\mathrm{CD} 25+$ Foxp3 $+\mathrm{T}$ regulatory cells. J Immunol (2009) 183(1):145-54. doi:10.4049/ jimmunol.0803277

107. Haribhai D, Williams JB, Jia S, Nickerson D, Schmitt EG, Edwards B, et al. A requisite role for induced regulatory $\mathrm{T}$ cells in tolerance based on expanding antigen receptor diversity. Immunity (2011) 35(1):109$22 . \quad$ doi:10.1016/j.immuni. 2011.03.029

108. Schreiber TH, Wolf D, Bodero M, Podack E. Tumor antigen specific iTreg accumulate in the tumor microenvironment and suppress therapeutic vaccination. Oncoimmunology (2012) doi:10.4161/onci.20298

109. Ladoire S, Martin F, Ghiringhelli F. Prognostic role of FOXP3+ regulatory $\mathrm{T}$ cells infiltrating human carcinomas: the paradox of colorectal cancer. Cancer Immunol Immunother (2011) 60(7):909-18. doi:10.1007/s00262-011-1046-y

110. Lahl K, Loddenkemper C, Drouin C, Freyer J, Arnason J, Eberl G, et al. Selective depletion of Foxp3+ regulatory $\mathrm{T}$ cells induces a scurfy-like disease. $J$
Exp Med (2007) 204(1):57-63. doi:10.1084/jem.20061852

111. Houot R, Levy R. T-cell modulation combined with intratumoral $\mathrm{CpG}$ cures lymphoma in a mouse model without the need for chemotherapy. Blood (2009) 113(15):3546-52. doi:10.1182/ blood-2008-07-170274

112. Klages K, Mayer CT, Lahl K, Loddenkemper C, Teng MW, Ngiow SF, et al. Selective depletion of Foxp3 + regulatory T cells improves effective therapeutic vaccination against established melanoma. Cancer Res (2010) 70(20):7788-99. doi:10.1158/ 0008-5472.CAN-10-1736

113. Teng MW, Swann JB, von Scheidt B, Sharkey J, Zerafa N McLaughlin N, et al. Multiple antitumor mechanisms downstream of prophylactic regulatory T-cell depletion. Cancer Res (2010) 70(7):2665-74. doi:10. 1158/0008-5472.CAN-09-1574

114. Yamaguchi T, Hirota K, Nagahama K, Ohkawa K, Takahashi $T$, Nomura $T$, et al. Control of immune responses by antigen-specific regulatory $\mathrm{T}$ cells expressing the folate receptor. Immunity (2007) 27(1):145-59. doi:10. 1016/j.immuni.2007.04.017

115. Oleinika K, Nibbs RJ, Graham GJ, Fraser AR. Suppression, subversion and escape: the role of regulatory $\mathrm{T}$ cells in cancer progression. Clin Exp Immunol (2013) 171(1):36$45 . \quad$ doi:10.1111/j.13652249.2012.04657.x

116. Audia S, Nicolas A, Cathelin D, Larmonier N, Ferrand C, Foucher $\mathrm{P}$, et al. Increase of $\mathrm{CD} 4+\mathrm{CD} 25+$ regulatory $\mathrm{T}$ cells in the peripheral blood of patients with metastatic carcinoma: a Phase I clinical trial using cyclophosphamide and immunotherapy to eliminate $\mathrm{CD} 4+\mathrm{CD} 25+$ $\mathrm{T}$ lymphocytes. Clin Exp Immunol (2007) 150(3):52330 doi:10.1111/j.13652249.2007.03521.x

117. Ercolini AM, Ladle BH, Manning EA, Pfannenstiel LW, Armstrong TD, Machiels JP, et al. Recruitment of latent pools of highavidity $\mathrm{CD} 8(+) \mathrm{T}$ cells to the antitumor immune response. $J$ Exp Med (2005) 201(10):1591602. doi:10.1084/jem.20042167

118. Ghiringhelli F, Menard C, Puig PE, Ladoire S, Roux
S, Martin F, et al. Metronomic cyclophosphamide regimen selectively depletes $\mathrm{CD} 4+\mathrm{CD} 25+$ regulatory $\mathrm{T}$ cells and restores $\mathrm{T}$ and $\mathrm{NK}$ effector functions in end stage cancer patients. Cancer Immunol Immunother (2007) 56(5):641-8. doi:10.1007/ s00262-006-0225-8

119. Lutsiak ME, Semnani RT, De Pascalis R, Kashmiri SV, Schlom J, Sabzevari H. Inhibition of CD4(+)25+ $\mathrm{T}$ regulatory cell function implicated in enhanced immune response by low-dose cyclophosphamide. Blood (2005) 105(7):2862-8. doi:10.1182/ blood-2004-06-2410

120. de Vries IJ, Castelli C, Huygens C, Jacobs JF, Stockis J, SchulerThurner B, et al. Frequency of circulating Tregs with demethylated FOXP3 intron 1 in melanoma patients receiving tumor vaccines and potentially Treg-depleting agents. Clin Cancer Res (2011) 17(4):841-8. doi:10.1158/10780432.CCR-10-2227

121. Walter S, Weinschenk T, Stenzl A, Zdrojowy R, Pluzanska A, Szczylik C, et al. Multipeptide immune response to cancer vaccine IMA901 after single-dose cyclophosphamide associates with longer patient survival. Nat Med (2012) 18(8):1254-61. doi: $10.1038 / \mathrm{nm} .2883$

122. Mougiakakos D, Johansson CC, Kiessling R. Naturally occurring regulatory $\mathrm{T}$ cells show reduced sensitivity toward oxidative stress-induced cell death. Blood (2009) 113(15):3542-5. doi:10. 1182/blood-2008-09-181040

123. Park HJ, Kusnadi A, Lee EJ, Kim WW, Cho BC, Lee IJ, et al. Tumor-infiltrating regulatory $\mathrm{T}$ cells delineated by upregulation of PD- 1 and inhibitory receptors. Cell Immunol (2012) 278(1-2): 76-83. doi:10.1016/j.cellimm. 2012.07.001

124. Curran MA, Montalvo W, Yagita H, Allison JP. PD-1 and CTLA-4 combination blockade expands infiltrating $\mathrm{T}$ cells and reduces regulatory $\mathrm{T}$ and myeloid cells within B16 melanoma tumors. Proc Natl Acad Sci U $S$ A (2010) 107(9):4275-80. doi:10.1073/pnas.0915174107

125. McHugh RS, Whitters MJ, Piccirillo CA, Young DA, Shevach EM, Collins $M$, et al. CD4(+)CD25(+) immunoregulatory $\mathrm{T}$ cells: gene expression analysis reveals a functional 
role for the glucocorticoidinduced TNF receptor. Immunity (2002) 16(2):311$23 . \quad$ doi:10.1016/S10747613(02)00280-7

126. Cohen AD, Schaer DA, Liu C, Li Y, Hirschhorn-Cymmerman D, Kim SC, et al. Agonist anti-GITR monoclonal antibody induces melanoma tumor immunity in mice by altering regulatory $\mathrm{T}$ cell stability and intra-tumor accumulation. PLoS ONE (2010) 5(5):e10436. doi:10. 1371/journal.pone.0010436

127. Ko K, Yamazaki S, Nakamura K, Nishioka T, Hirota K, Yamaguchi $\mathrm{T}$, et al. Treatment of advanced tumors with agonistic anti-GITR $\mathrm{mAb}$ and its effects on tumor-infiltrating Foxp3+CD25+CD4+ regulatory $\mathrm{T}$ cells. $J \quad \operatorname{Exp}$ Med (2005) 202(7):885-91. doi:10.1084/jem.20050940

128. Mitsui J, Nishikawa H, Muraoka D, Wang L, Noguchi T, Sato E, et al. Two distinct mechanisms of augmented antitumor activity by modulation of immunostimulatory/inhibitory signals. Clin Cancer Res (2010) 16(10):278191. doi:10.1158/1078-0432.CCR09-3243

129. Hodi FS, O'Day SJ, McDermott DF, Weber RW, Sosman JA, Haanen JB, et al. Improved survival with ipilimumab in patients with metastatic melanoma. $N$ Engl $J$ Med (2010) 363(8):711-23. doi:10.1056/NEJMoa1003466
130. Mandapathil M, Hilldorfer B, Szczepanski MJ, Czystowska M, Szajnik M, Ren $\mathrm{J}$, et al. Generation and accumulation of immunosuppressive adenosine by human CD4+CD25highFOXP3+ regulatory $\mathrm{T}$ cells. $J$ Biol Chem (2010) 285(10):7176-86 doi:10.1074/jbc.M109.047423

131. Mandapathil M, Szczepanski MJ, Szajnik M, Ren J, Jackson EK, Johnson JT, et al. Adenosine and prostaglandin E2 cooperate in the suppression of immune responses mediated by adaptive regulatory $\mathrm{T}$ cells. $J$ Biol Chem (2010) 285(36):27571-80. doi:10.1074/jbc.M110.127100

132. Whiteside TL, Mandapathil M, Schuler P. The role of the adenosinergic pathway in immunosuppression mediated by human regulatory $\mathrm{T}$ cells (Treg). Curr Med Chem (2011) 18(34):5217-23. doi:10. 2174/092986711798184334

133. Conroy H, Galvin KC, Higgins SC, Mills KH. Gene silencing of TGF-betal enhances antitumor immunity induced with a dendritic cell vaccine by reducing tumor-associated regulatory $\mathrm{T}$ cells. Cancer Immunol Immunother (2012) 61(3):425-31. doi:10.1007/s00262-011-1188-y

134. Kim JM, Rasmussen JP, Rudensky AY. Regulatory $\mathrm{T}$ cells prevent catastrophic autoimmunity throughout the lifespan of mice.
Nat Immunol (2007) 8(2):191-7. doi:10.1038/ni1428

135. Sakaguchi S, Powrie F, Ransohoff RM. Re-establishing immunological self-tolerance in autoimmune disease. Nat Med (2012) 18(1):54-8. doi:10.1038/nm0412-630a

136. Schwartzentruber DJ, Lawson DH, Richards JM, Conry RM, Miller DM, Treisman J, et al. gp100 Peptide vaccine and interleukin-2 in patients with advanced melanoma. $N$ Engl J Med (2011) 364(22):2119-27. doi:10.1056/NEJMoa1012863

137. Strauss L, Bergmann C, Gooding W, Johnson JT, Whiteside TL. The frequency and suppressor function of CD4+CD25highFoxp3+ T cells in the circulation of patients with squamous cell carcinoma of the head and neck. Clin Cancer Res (2007) 13(21):6301-11. doi:10.1158/1078-0432.CCR-071403

138. Mandapathil M, Szczepanski MJ, Szajnik M, Ren J, Lenzner DE, Jackson EK, et al. Increased ectonucleotidase expression and activity in regulatory $\mathrm{T}$ cells of patients with head and neck cancer. Clin Cancer Res (2009) 15(20):6348-57. doi:10.1158/1078-0432.CCR-091143

139. Szczepanski MJ, Szajnik M Czystowska M, Mandapathil M, Strauss L, Welsh A et al. Increased frequency and suppression by regulatory $\mathrm{T}$ cells in patients with acute myelogenous leukemia. Clin Cancer Res (2009) 15(10):3325-32. doi:10.1158/1078-0432.CCR-083010

140. Geiger TL, Tauro S. Nature and nurture in Foxp3(+) regulatory $\mathrm{T}$ cell development, stability, and function. Hum Immunol (2012) 73(3): 232-9. doi:10.1016/j.humimm. 2011.12.012

Conflict of Interest Statement: The authors declare that the research was conducted in the absence of any commercial or financial relationships that could be construed as a potential conflict of interest.

Received: 28 April 2013; accepted: 27 June 2013; published online: 11 July 2013.

Citation: Adeegbe DO and Nishikawa $H$ (2013) Natural and induced T regulatory cells in cancer. Front. Immunol. 4:190. doi: 10.3389/fimmu.2013.00190

This article was submitted to Frontiers in Immunological Tolerance, a specialty of Frontiers in Immunology.

Copyright (C) 2013 Adeegbe and Nishikawa. This is an open-access article distributed under the terms of the Creative Commons Attribution License, which permits use, distribution and reproduction in other forums, provided the original authors and source are credited and subject to any copyright notices concerning any third-party graphics etc. 